\title{
Redo surgery after transcatheter aortic valve replacement with a balloon-expandable valve
} \author{
Japan

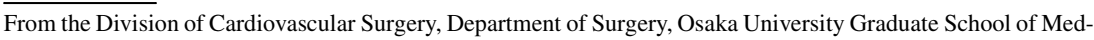 \\ icine, Suita, Japan. \\ Disclosures: The authors reported no conflicts of interest. \\ The Journal policy requires editors and reviewers to disclose conflicts of interest and to decline handling or re- \\ viewing manuscripts for which they may have a conflict of interest. The editors and reviewers of this article \\ have no conflicts of interest. \\ Received for publication May 27, 2020; revisions received May 27, 2020; accepted for publication June 16, 2020; \\ available ahead of print June 22, 2020. \\ Address for reprints: Yoshiki Sawa, MD, PhD, Division of Cardiovascular Surgery, Osaka University Graduate \\ School of Medicine, 2-15 Yamadaoka, Suita 565-0871, Japan (E-mail: sawa-p@ surg1.med.osaka-u.ac.jp). \\ JTCVS Techniques 2020;3:72-4 \\ 2666-2507 \\ Copyright (C) 2020 The Authors. Published by Elsevier Inc. on behalf of The American Association for Thoracic \\ Surgery. This is an open access article under the CC BY-NC-ND license (http://creativecommons.org/licenses/by- \\ nc-nd/4.0/). \\ https://doi.org/10.1016/j.xjtc.2020.06.018
}

Taro Nakazato, MD, Koichi Toda, MD, PhD, Toru Kuratani, MD, PhD, and Yoshiki Sawa, MD, PhD, Suita, $\checkmark$ Video clip is available online.

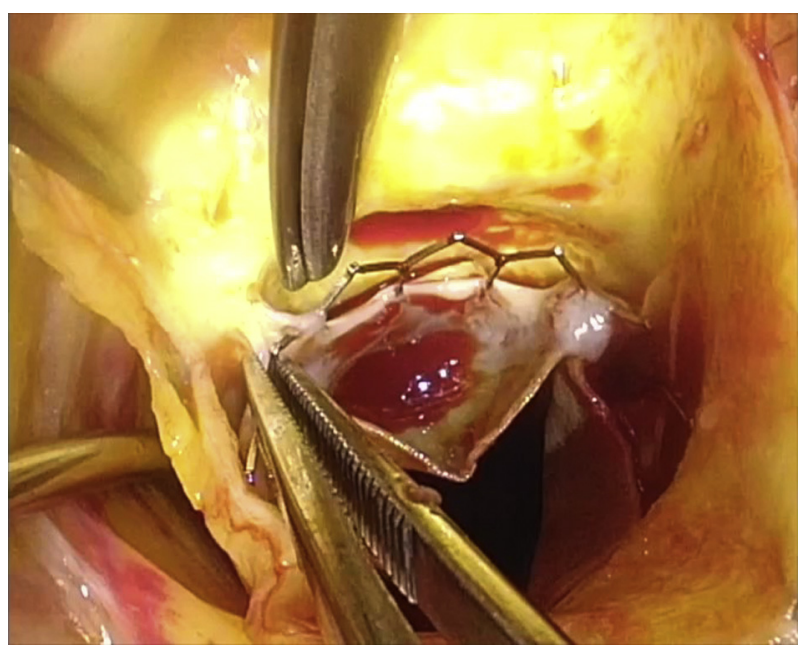

VIDEO 1. The video demonstrates the technique for surgical aortic valve replacement after transcatheter aortic valve replacement (TAVR) with a balloon-expandable valve. After careful dissection is initiated between the Valsalva sinus and the frame of TAVR valve and securing space for a surgical nipper, the frame is cut in stage until the bottom of the frame and the radial force is released. After the frame of the TAVR valve was completely divided, we grasped the end of the divided valve with a Kelly clamp and carefully peeled off the TAVR valve from the Valsalva sinus and the aortic annulus by wrapping the TAVR valve around the Kelly clamp to facilitate careful dissection of the adhesions by electrocautery. Video available at: https://www.jtcvs.org/article/S2666-2507(20)30296-0/ fulltext.

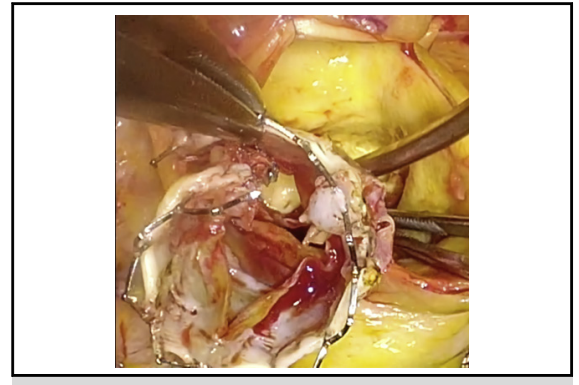

Balloon-expandable valve safely removed by cutting wire frame and releasing radial force.

\section{CENTRAL MESSAGE}

Transcatheter balloonexpandable valves can be safely removed without aortic root disruption by cutting the frame wire and releasing its radial force.

See Commentaries on pages 75 and 77.
Transcatheter aortic valve replacement (TAVR) is a common surgical intervention in intermediate- and high-risk patients with severe aortic stenosis (AS). ${ }^{1}$ After TAVR, some patients develop structural valve deterioration (SVD) or prosthetic valve endocarditis and may require surgical aortic valve replacement (SAVR), although though this has been reported only rarely., Owing to adhesion of the valve to the surrounding tissue, removing a TAVR valve poses a great risk, because it may disrupt the aortic root. Here we describe our technique for SAVR after TAVR using a balloonexpandable valve.

\section{SURGICAL TECHNIQUE}

Our surgical technique is demonstrated in Video 1. In this patient, the TAVR valve was covered with the intima and adhered firmly to the aortic root and subvalvular tissue, including the anterior leaflet of the mitral valve. Initial dissection between the Valsalva sinus and the valve frame had to be performed carefully so as not to damage surrounding tissues (Figure 1, A). After securing 

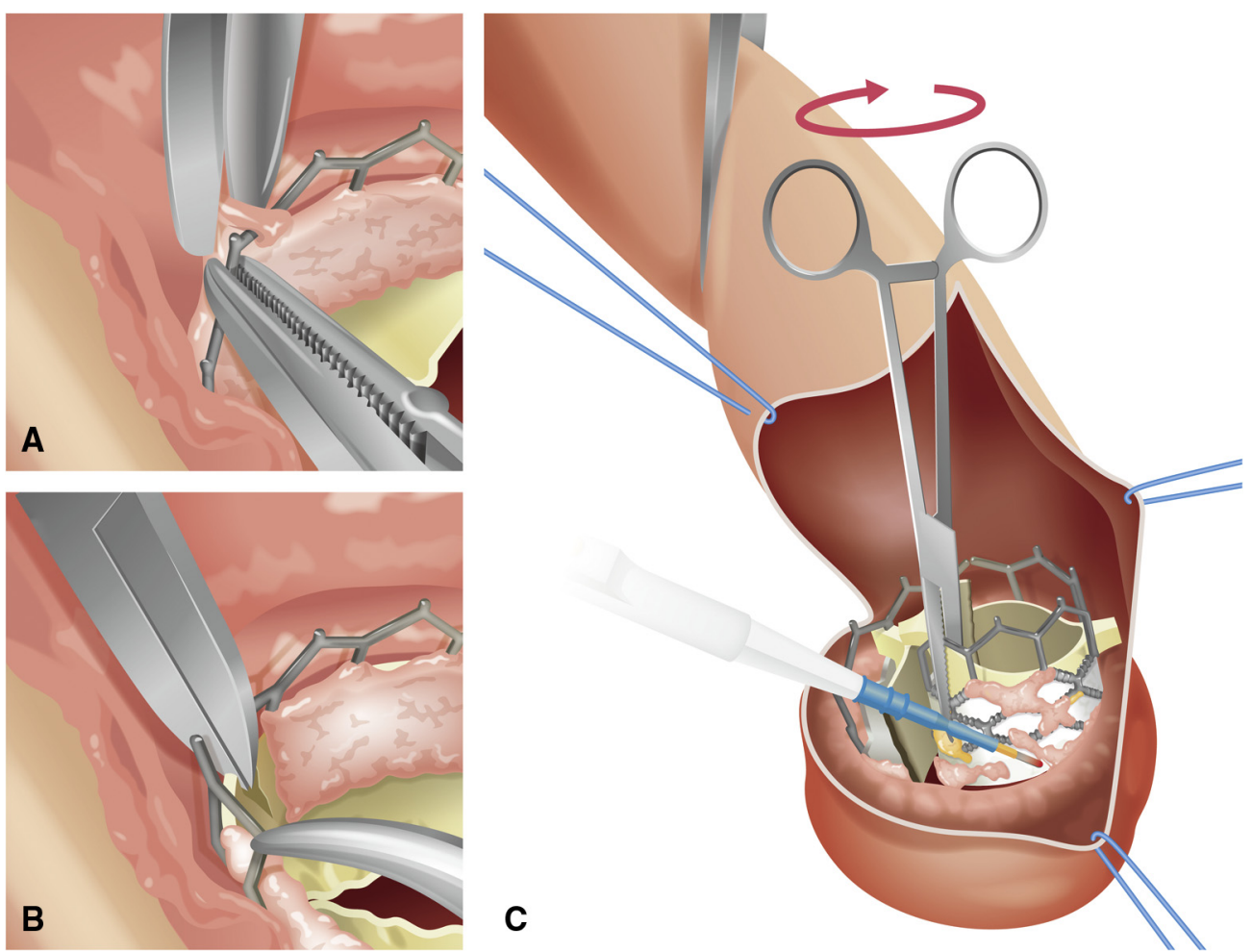

FIGURE 1. A, Careful dissection is initiated between the Valsalva sinus and the frame of transcatheter aortic valve replacement (TAVR) valve. B, After securing space for a surgical nipper by careful dissection, the frame is cut in stages until the bottom of the frame and the radial force is released. C, Once the frame of the TAVR valve is completely divided, the end of the divided valve is grasped with a Kelly clamp and carefully peeled off the TAVR valve from the Valsalva sinus and aortic annulus by wrapping the TAVR valve around the Kelly clamp to facilitate careful dissection of the adhesions around the TAVR valve by electrocautery.

space for a surgical nipper, the frame was cut longitudinally at the noncoronary cusp (Figure $1, B$ ). After the frame of the TAVR valve was completely divided, the radial force of the valve was released. While grasping the end of the divided valve with a Kelly clamp, we carefully peeled off the TAVR valve from the aortic root by wrapping the TAVR valve around the Kelly clamp to facilitate careful dissection by electrocautery
(Figure 1,C). After removal of the TAVR valve, the native aortic valves were excised, and the prosthetic valve was fixed in place.

\section{RESULTS}

In our institution, between October 2009 and September 2019, 773 patients underwent TAVR, and 491 patients received a balloon-expandable valve; of

TABLE 1. Patient characteristics, operative procedures, and postoperative details

\begin{tabular}{|c|c|c|c|c|c|c|c|c|c|c|}
\hline Patient & $\begin{array}{l}\text { Age, } \\
\text { y/sex }\end{array}$ & $\begin{array}{c}\text { STS } \\
\text { score } \\
\text { before } \\
\text { TAVR }\end{array}$ & Details on TAVR & $\begin{array}{c}\text { Time } \\
\text { from } \\
\text { SAVR to } \\
\text { TAVR, d }\end{array}$ & $\begin{array}{l}\text { Indication } \\
\text { for SAVR }\end{array}$ & $\begin{array}{c}\text { STS } \\
\text { score } \\
\text { before } \\
\text { SAVR }\end{array}$ & $\begin{array}{l}\text { Prosthetic valve, } \\
\text { type and size }\end{array}$ & $\begin{array}{c}\text { Concomitant } \\
\text { procedure }\end{array}$ & $\begin{array}{c}\text { Aortic } \\
\text { cross- } \\
\text { clamp/CPB } \\
\text { time, min }\end{array}$ & $\begin{array}{c}\text { Hospital } \\
\text { death }\end{array}$ \\
\hline 1 & $81 / \mathrm{M}$ & 8.0 & SAPIEN XT $26 \mathrm{~mm}$ & 38 & PVE & 41.9 & SJM Epic, $21 \mathrm{~mm}$ & None & $136 / 173$ & None \\
\hline 2 & 78/M & 5.8 & $\begin{array}{l}\text { SAPIEN } 23 \mathrm{~mm} \\
\text { SAPIEN XT } 23 \mathrm{~mm}\end{array}$ & 248 & AS (SVD) & 8.6 & SJM Regent, $23 \mathrm{~mm}$ & CABG & $137 / 235$ & None \\
\hline 3 & $69 / \mathrm{M}$ & 2.8 & SAPIEN $326 \mathrm{~mm}$ & 339 & AR (PVL) & 5.6 & $\begin{array}{l}\text { INSPILIS RESILIA, } \\
23 \mathrm{~mm}\end{array}$ & MAP, TAP & $156 / 222$ & None \\
\hline 4 & $54 / \mathrm{F}$ & 1.64 & SAPIEN XT $20 \mathrm{~mm}$ & 882 & ASR (SVD) & 1.9 & ATS-AP, $16 \mathrm{~mm}$ & CABG & $127 / 341$ & $\begin{array}{l}\text { POD 9, } \\
\text { MOF }\end{array}$ \\
\hline
\end{tabular}

STS, Society of Thoracic Surgeons; $T A V R$, transcatheter aortic valve replacement; $S A V R$, surgical aortic valve replacement; $C P B$, cardiopulmonary bypass; $M$, male; $P V E$, prosthetic valve endocarditis; $A S$, aortic valve stenosis; $S V D$, structural valve deterioration; $C A B G$, coronary artery bypass grafting; $A R$, aortic valve regurgitation; $P V L$, paravalvular leakage; $M A P$, mitral annuloplasty; $T A P$, tricuspid annuloplasty; $F$, female; $A S R$, aortic valve stenosis and regurgitation; $P O D$, postoperative day; $M O F$, multiple organ failure. 
them, 4 required SAVR using the foregoing technique. The patients' details are summarized in Table 1; informed consent was obtained from each patient. In patient 1 , vegetation was found only in the TAVR leaflets, and the frame of the TAVR valve was firmly adhered to the aortic root. Therefore, it was difficult to remove the TAVR valve without releasing the radial force by cutting the frame.

Patient 2 had a history of hemodialysis for 10 years and underwent TAVR. Two years after the first TAVR, he required a second TAVR because of SVD. Eight months after the second TAVR, SVD occurred again and we opted for SAVR. First, we removed the calcified inner valve and then the outer one, using the same technique as for patient 1 . Dissection between 2 TAVR valves was easier than anticipated; however, removal of the outer TAVR valve was more difficult because of the thicker adhesion to the aortic root.

For patient 3, we chose open heart surgery because of paravalvular leakage and functional mitral regurgitation associated with dilated cardiomyopathy. Patient 4 was a female with a body surface area of $1.25 \mathrm{~m}^{2}$ and a past medical history of mucopolysaccharidosis who had undergone mitral valve replacement using a 20-mm ATSAP valve for mitral stenosis 14 years earlier, which was complicated with postoperative severe diastolic dysfunction of both ventricles and necessitated mechanical circulatory support. Eleven years after mitral valve replacement, she developed severe AS and underwent TAVR. At 2-1/2 years after TAVR, SAVR was required for AS owing to SVD associated with deposition of acid mucopolysaccharide. Unfortunately, she died of a stuck mitral mechanical valve. The other patients were discharged without any complications.

\section{DISCUSSION}

Although our technique provides good exposure of the TAVR valve and surrounding tissues and may facilitate safe removal of the TAVR valve, careful dissection is important to prevent damage to the aortic root. In particular, the initial careful dissection of the tissues attached to the frame is important to secure space for a surgical nipper, and careful cutting of the frame in stage is crucial in this technique. Although we could use electrocautery to peel off the TAVR valve without causing damage to the aortic root, cautery can arc the chromium cobalt and may cause thermal damage. This may be a pitfall of our technique, and a 15-blade knife may be less traumatic for peeling off the TAVR valve.

The superiority of TAVR in early outcomes has been demonstrated even in low-risk patients. ${ }^{4}$ The number of younger patients undergoing TAVR is expected to increase, and more patients will require SAVR after TAVR. Especially in patients with hemodialysis or metabolic disease, such as in our cases, there may be risk of early SVD after TAVR. Although our technique may be useful for safe removal of the TAVR valve, careful patient selection is mandatory for TAVR to avoid early SVD.

\section{References}

1. Leon MB, Smith CR, Mack MJ, Makkar RR, Svensson LG, Kodali SK, et al. Transcatheter or surgical aortic-valve replacement in intermediate-risk patients. N Engl J Med. 2016;374:1609-20.

2. Didier R, Eltchaninoff H, Donzeau-Gouge P, Chevreul K, Fajadet J, Leprince P, et al. Five-year clinical outcome and valve durability after transcatheter aortic valve replacement in high-risk patients. Circulation. 2018;138:2597-607.

3. Regueiro A, Linke A, Latib A, Ihlemann N, Urena M, Walther T, et al. Association between transcatheter aortic valve replacement and subsequent infective endocarditis and in-hospital death. JAMA. 2016;316:1083-92.

4. Mack MJ, Leon MB, Thourani VH, Makkar R, Kodali SK, Russo M, et al. Transcatheter aortic-valve replacement with a balloon-expandable valve in low-risk patients. N Engl J Med. 2019;380:1695-705. 